\title{
Ruptura de quiste hidatídico hepático hacia cavidad torácica por trauma tóraco- abdominal. Dificultades en el diagnóstico
}

\author{
Rupture of a hepatic hydatid cyst towards the chest cavity after an abdominal-chest trauma. Difficulties in \\ the diagnosis
}

Enrique Castañeda Saldaña ${ }^{1, a ; ~ 2, b}$, Olenka Antonella Sapallanay Ojeda ${ }^{1, c}$

\section{RESUMEN}

La equinococosis es una infección zoonótica causada por el cestodo del género Echinococcus, endémica en muchas regiones del Perú. Los quistes hidatídicos habitualmente se ubican en el hígado y pulmón, siendo infrecuente tanto su localización en otros órganos como la hidatidosis múltiple. La mayoría de ellos son asintomáticos y de hallazgo incidental, aunque también pueden ocurrir complicaciones, como su ruptura espontánea o traumática que tiene una mínima incidencia (3-17\%), siendo insólito que se dé hacia el tórax. Se presenta el caso de un paciente con ruptura de quistes hidatídicos hepáticos hacia la cavidad pleural, por traumatismo tóraco-abdominal, que al constituir una presentación excepcional de la patología originó dificultades en su reconocimiento inicial teniéndose como diagnóstico diferencial un hemotórax masivo. Este finalmente fue superado por la revisión de imágenes tomográficas con las que se concluyó una hidatidosis hepática complicada.

PALABRAS CLAVE: Equinococosis hepática, ruptura, heridas y traumatismos, hemotórax. (Fuente: DeCS BIREME).

\section{SUMMARY}

Cystic hydatidosis is a zoonotic infection caused by the cestode Echinococcus, which is endemic in many regions of Peru. Hydatid cysts are usually located in the liver and lungs, locations elsewhere are rare as well as multiple hydatidosis. Most of the hydatid cysts are asymptomatic and are found incidentally. Rare complications may arise such as spontaneous or traumatic rupture (3-17\%), it is very infrequent that the hydatid cyst rupture towards the chest wall. We present a case of a patient who suffered the rupture of hepatic cysts into the pleural cavity after an abdominal-chest trauma, the rarity of this event made the identification of the problem more difficult to be confused with massive hemothorax. Careful review of the CT-Scan images allowed to reach the correct diagnsosis.

KEYWORDS: hepatic echinococcosis, rupture, wounds and injuries, hemothorax. (Source: MeSH NLM).

Facultad de Medicina Alberto Hurtado, Universidad Peruana Cayetano Heredia. Lima, Perú.

2 Departamento de Cirugía, Servicio de Cirugía de Tórax y Cardiovascular. Hospital Cayetano Heredia. Lima, Perú.

a Profesor Principal de Cirugía

b Jefe de Servicio;

c Estudiante de pregrado. 


\section{INTRODUCCIÓN}

La hidatidosis o equinococosis es una infección parasitaria que afecta al ser humano, es causada por el estadio larvario del género Echinococcus, cestodo perteneciente al filum de los platelmintos ${ }^{(1,2)}$. Existen especies de importancia en salud pública, a partir de las cuales se reconocen clínicamente tres morfologías amplias de la enfermedad: Echinococcus granulosus, responsable de la equinococosis quística; Echinococcus multilocularis, causante de la equinococosis alveolar; y finalmente Echinococcus vogeli y Echinococcus oligarthrus, que originan la equinococosis poliquística (2-4).

La presentación más frecuente en humanos es la equinococosis quística representando más del $95 \%$ de los 2-3 millones de casos globales estimados. Se considera una zoonosis cosmopolita, siendo más común en países donde se cría ganado ovino y los perros tienen acceso a las vísceras infectadas, además de mala salubridad, higiene y pobreza ${ }^{(4,5)}$. En el Perú la tasa de hidatidosis humana es de 7-11/100 000 habitantes, afecta principalmente las zonas ganaderas de la Sierra central y sur, siendo regiones hiperendémicas Pasco, Huancavelica, Junín, Puno, Cusco y Arequipa ${ }^{(6)}$.

El hombre cumple el rol de huésped accidental mediante la ingesta de huevos de Echinococcus en agua o vegetales contaminados con las heces de los huéspedes definitivos ${ }^{(3-5)}$. Los quistes hidatídicos pueden localizarse en casi cualquier tejido; sin embargo, los órganos más perjudicados son el hígado (75\%), pulmón $(15 \%)$, riñón $(3 \%)$, bazo $(1-8 \%)$, médula ósea $(0,5-4 \%)$ y cerebro $(1 \%)^{(2)}$.

La hidatidosis hepática inicialmente es asintomática, los síntomas resultan de la compresión de estructuras adyacentes por el quiste o distensión de la cápsula de Glisson ${ }^{(7)}$. Su complicación más grave y rara es la ruptura de los quistes, si es directa hacia la cavidad peritoneal, pleural o pared abdominal es más severa aún, a diferencia de la forma contenida, en la cual se conservan el endocisto y pericisto intactos (8). La ruptura puede ser espontánea o posterior a un traumatismo cerrado, principalmente a nivel peritoneal y con muy poca frecuencia hacia la cavidad torácica (0,6-16\% de los casos), donde causa un espectro de lesiones en la pleura, el parénquima pulmonar y los bronquios ${ }^{(9,10)}$.

El reporte tuvo el propósito de presentar el caso de un paciente con quistes hidatídicos hepáticos rotos por trauma tóraco-abdominal cerrado, vertidos hacia la cavidad torácica debido a ruptura diafragmática asociada; asimismo, se discute la confusión que puede generar en el diagnóstico diferencial.

\section{PRESENTACIÓN DEL CASO}

Varón de 38 años originario del área rural de Puno, ciudad de la sierra peruana, quien radica en Lima, Perú, desde hace cinco años. Como antecedente epidemiológico de importancia, refirió contacto cercano en la adolescencia con animales domésticos (perros) y ganado (vacuno, porcino y ovino). Acudió a emergencia en estado de confusión producto de un accidente de tránsito (conductor) presentando disnea severa agravada por el decúbito dorsal, dolor intenso torácico y abdominal en flanco e hipocondrio derecho. Al examen clínico estaba confuso, y presentaba escoriaciones en tórax posterior, murmullo vesicular disminuido, matidez en tercio inferior del hemitórax derecho, taquipnea (26 x minuto) y saturación de $94 \%$ a $\mathrm{FiO}_{2}$ ambiental.

El análisis de gases arteriales mostró $\mathrm{PCO}_{2} 34,3$ mm Hg; $\mathrm{PO}_{2} 76,3 \mathrm{~mm} \mathrm{Hg} ; \mathrm{PO}_{2}$ (a) / FO (I) $_{\mathrm{c}} 363 \mathrm{~mm}$ $\mathrm{Hg} ; \mathrm{SatO}_{2} 94,1 \%$. La radiografía de tórax mostró opacidad de los dos tercios inferiores del hemitórax derecho (figura 1).

El diagnóstico inicial fue traumatismo torácico cerrado con hemotórax masivo derecho, procediéndose a colocar un tubo de drenaje torácico derecho; sin embargo, llamó la atención que el drenaje fuera tan solo

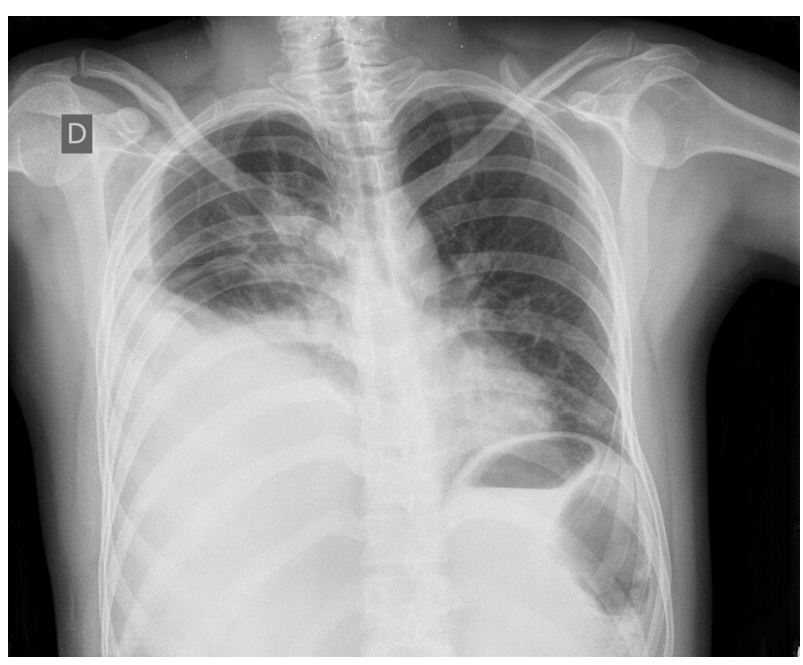

Figura 1. Radiografía de tórax al ingreso del paciente que muestra opacidad de los dos tercios inferiores del hemitórax derecho. 
$100 \mathrm{ml}$ de líquido sero-hemático, y a través del dren se observó obstrucción por contenido membranoso. Se revisó el caso, indicándose tomografía espiral multicorte tóraco-abdominal y evaluando las imágenes de la misma se constató opacidad heterogénea con múltiples cavidades quísticas en espacio pleural cohesionada con la zona supra hepática; por ello se confirmó el diagnóstico de hidatidosis hepática con ruptura diafragmática abierta hacia cavidad pleural (figura 2). Además, se notó quiste hidatídico esplénico no roto.

El paciente se programó a cirugía de emergencia con un perfil pre quirúrgico completo, resaltando en el hemograma la ausencia de eosinofilia y la hemoglobina en valores normales que alejaba la posibilidad de

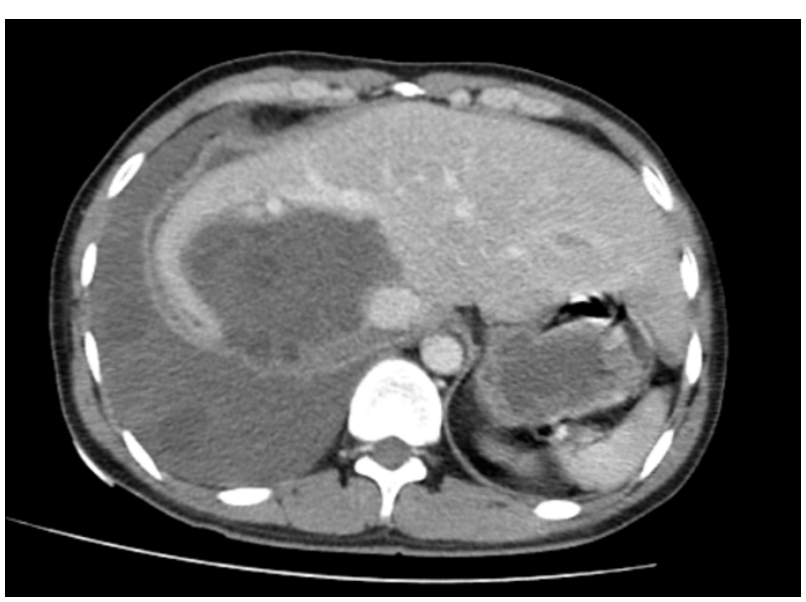

Figura 2: Tomografía tóraco-abdominal: muestra quistes en cavidad pleural, intrahepáticos, con solución de continuidad de diafragma y quiste esplénico.

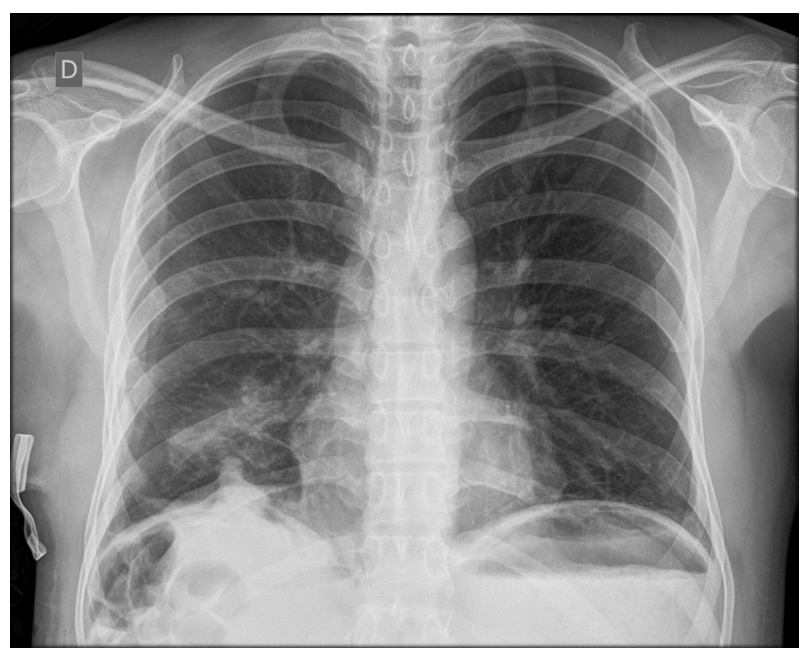

Figura 3. Radiografía postoperatoria que muestra re expansión completa del pulmón derecho. hemotórax (hemoglobina: 15,1 g/dl; hematocrito: 45\%; leucocitos: $8,84 \times 10^{3} / \mathrm{mm}^{3}$; neutrófilos 76,7\%; eosinófilos $0 \%$; basófilos $0,1 \%$; linfocitos $12,3 \%$ ).

Se realizó toracotomía postero-lateral derecha estándar con ingreso a la cavidad pleural por el sexto espacio intercostal derecho, previa colocación de abundantes compresas embebidas con $\mathrm{NaCl} 20 \%$. Se encontró abundante líquido serohemático no fétido con múltiples quistes de distintos tamaños y estadios de evolución más membranas hidatídicas, todas provenientes de una cavidad quística subdiafragmática de $20 \times 30 \mathrm{~cm}$ vertida en espacio pleural a través de una ruptura asociada del tendón central derecho diafragmático. Se evacuó el contenido total (5,22 litros) hallándose atelectasia de los lóbulos medio e inferior derechos por adherencia quística al parénquima pulmonar; luego se verificó por dígito-palpación que no había quistes en el pulmón. Seguidamente, se abordó la cavidad quística hepática retirando todos los quistes y completando el lavado de la cavidad hepática subdiafragmática y de la cavidad pleural ( $\mathrm{NaCl} 20 \%$ diluido y 5 litros de $\mathrm{NaCl} 0,9 \%$ ), asimismo, se colocaron dos drenajes pleurales (uno antero-superior y otro postero-basal). Finalmente se realizó rafia del diafragma con puntos separados y se cerró la incisión por planos, colocando $\mathrm{NaCl} 20 \%$ sobre el tejido en cada plano afrontado.

La evolución clínica del paciente fue favorable, en la radiografía de tórax post-quirúrgica se evidenció re expansión completa del pulmón derecho (figura 3), por lo que fue dado de alta al $12^{\circ}$ día postoperatorio, con indicación de albendazol $400 \mathrm{mg}$ /día por 12 meses, recomendando controles trimestrales y evaluación por cirugía general para programación quirúrgica de quiste esplénico. No se tiene información sobre el seguimiento posterior al alta.

\section{DISCUSIÓN}

La hidatidosis es una infección parasitaria silente hasta que los quistes hidatídicos crecen y generan síntomas, lo que puede tardar mucho tiempo haciendo que la mayoría se descubra accidentalmente por técnicas de imagen ${ }^{(7,11,12)}$. La sintomatología depende de su localización, de las reacciones tóxicas inducidas, y de su efecto local determinado por su viabilidad ${ }^{(12)}$. Habitualmente, la patología afecta el hígado (> 65\%) y los pulmones (15\%), se presenta como quiste único (75\%) en un solo órgano ( $85-90 \%$ de pacientes) siendo la forma más benigna y de tratamiento más sencillo; con menor frecuencia $(20-40 \%$ de casos) pueden 
encontrarse múltiples quistes que dañan distintos órganos de forma irremediable ${ }^{(7,12)}$.

El caso presentado es insólito especialmente porque su descubrimiento no fue fortuito a través de métodos radiológicos o por la clínica esperada de una hidatidosis hepática (dolor en epigastrio o hipocondrio derecho, hepatomegalia e ictericia), sino por la rotura de quistes hepáticos hacia la cavidad pleural por un trauma, que al ser una presentación inusual generó dificultades en el diagnóstico ${ }^{(7,12)}$. Asimismo, se constataron quistes también en bazo, ubicación atípica ( $1-8 \%$ de casos) que representa el $4 \%$ de las localizaciones abdominales, los cuales junto a los quistes hepáticos corresponden a una hidatidosis múltiple que es infrecuente ${ }^{(13)}$.

El diagnóstico diferencial principal fue un hemotórax masivo derecho por el trauma tóracoabdominal, sospechado por los síntomas de disnea agravada al decúbito dorsal, dolor torácico, los signos en el examen físico, saturación en descenso, murmullo vesicular disminuido, taquipnea y matidez en tercio inferior del hemitórax derecho, y la opacidad en el mismo advertida en la radiografía inicial. Sin embargo, por la evaluación posterior a la colocación del dren torácico (escaso drenaje con contenido membranoso), la hemoglobina en niveles normales y la ausencia de choque hipovolémico, al solicitar la tomografía se confirmó que se trataba de una ruptura de quistes hepáticos y diafragmática con múltiples cavidades quísticas en espacio pleural. En adición, los síntomas y signos atribuidos al hemotórax correspondieron en realidad a la presentación clínica de la ruptura hidatídica, que se describe como dolor torácico, fiebre, trastornos respiratorios, signos de derrame pleural manifiesto, $\mathrm{y}$ algunas veces fenómenos alérgicos ${ }^{(11,14)}$.

Si bien en la hidatidosis hepática pueden surgir complicaciones como obstrucción biliar, infección secundaria y fistulización, la ruptura espontánea o postraumática de los quistes tiene una baja incidencia (3-17\%) ${ }^{(15)}$, siendo los más proclives aquellos superficiales, de gran tamaño y que resisten altas presiones ${ }^{(7)}$. Se da mayormente hacia la cavidad peritoneal (sobre todo en árbol biliar) y con menor frecuencia hacia la cavidad torácica $(0,6-16 \%$ de casos), complicación grave descrita por diferentes estudios como muy rara y de difícil diagnóstico ${ }^{(7-12)}$, como lo fue en el caso de nuestro paciente.

La ruptura se ve posibilitada por varios factores: la comunicación entre el quiste hepático con la cúpula diafragmática (a través del diafragma puede cruzar hacia pleura); la diferencia tóraco-abdominal de presiones (el contenido quístico es más propenso a ser vertido en la cavidad torácica); la corrosión tisular por contacto con la bilis y la erosión del diafragma por necrosis local ${ }^{(9,11)}$. De ello se infiere que la rotura diafragmática a causa del trauma se vio facilitada por el estado previo del músculo, probablemente corroído y erosionado por los quistes hepáticos; favoreciendo así el derrame del contenido quístico en la cavidad pleural.

Por otro lado, se sabe que mientras el quiste hidatídico madura parte de su contenido puede pasar a la circulación causando sensibilización, por ende, cuando se dan rupturas se pueden presentar reacciones inmunes severas con choque anafiláctico (20\%) y muerte; la eosinofilia se presenta en el $20-40 \%$ de casos y se asocia a rupturas recientes ${ }^{(15-17)}$. Es por ello que resaltó en el hemograma de nuestro paciente la ausencia de eosinofilia y choque anafiláctico pese a la rotura temprana de quistes de volumen significativo.

Otra consecuencia de la ruptura quística pleural es la siembra hidatídica de elementos fértiles que da lugar a una equinococosis secundaria ${ }^{(14)}$, por ello, la OMS sugiere el tratamiento médico como prevención que al inactivar protoescólices reduce su recurrencia ${ }^{(1,18)}$. El albendazol es el fármaco de elección, por lo que fue indicado a nuestro paciente según la dosis aconsejada (10-15 mg/kg/día por vía oral) dividida en dos tomas ${ }^{(12)}$. El tiempo de indicación fue de 12 meses tomando en cuenta la recomendación de una terapia postquirúrgica mínima de 6 meses en pacientes con quistes hepáticos o esplénicos rotos ${ }^{(19)}$.

De la mano con lo anterior, se debe valorar la respuesta a la terapia y las recidivas de la enfermedad por medio de controles clínicos, de imágenes y serológicos. Especialmente los quistes rotos ameritan un seguimiento posoperatorio riguroso para vigilar la recurrencia, pese a que su periodicidad no haya sido sistematizada ${ }^{(7)}$. Al alta de nuestro paciente se recomendaron controles trimestrales y evaluación por cirugía general para la programación quirúrgica del quiste esplénico.

Se presenta el caso por su ocurrencia infrecuente en forma de una escisión de quistes hidatídicos hepáticos asociada a ruptura diafragmática por un traumatismo cerrado tóraco-abdominal, con el consecuente vertimiento del contenido parasitario en la cavidad pleural. Por su excepcionalidad, la 
conclusión inicial fue de trauma torácico cerrado con hemotórax masivo derecho, hasta que no era coherente con la escasa cantidad de drenaje torácico y la presencia de membranas en el dren; hecho que sumado a la evaluación de las imágenes tomográficas replanteó el diagnóstico concluyente como hidatidosis hepática complicada.

\section{Página de declaración de financiamiento y conflicto de intereses:}

Los autores financiaron el reporte de caso; declaran no tener conflicto de interés.

\section{Contribución de autoría:}

ECS: Idea original, revisión y redacción detallada del artículo. OASO: Recopilación de información clínica, argumentación y redacción detallada del artículo.

\section{Correspondencia:}

Dr. Enrique Castañeda Saldaña.

Facultad de Medicina, Universidad Peruana Cayetano Heredia.

Av. Honorio Delgado 430, Lima 31, Perú.

Correo electrónico: enrique.castaneda@upch.pe

\section{REFERENCIAS BIBLIOGRÁFICAS}

1. Pinedo C, Valenzuela C, Cano P, et al. Derrame pleural izquierdo como primera manifestación de un quiste hidatídico. Rev Patol Respir. 2007; 10(2):8587.

2. Revoredo F, De Vinatea J, Reaño G, et al. Quiste hidatídico de páncreas: abordaje laparoscópico. Rev Gastroenterol Perú. 2016; 36(3):264-8.

3. Eckert J, Deplazes P. Biological, Epidemiological, and Clinical Aspects of Echinococcosis, a Zoonosis of Increasing Concern. Clin Microbiol. Rev. 2004; 17(1):107-135.

4. Acha P, Szyfres B. Cestodiasis. En: PAHO, editor. Zoonoses and communicable diseases common to man and animals: parasitoses. Vol 3. $3^{\mathrm{a}} \mathrm{ed}$. Washington, DC: PAHO; 2003. p. 165-222.

5. Craig P, McManus D, Lightowlers M, et al. Prevention and control of cystic echinococcosis. Lancet Infect Dis. 2007; 7(6):385-394.

6. Náquira C, Bullón F, Balvín G, Reyes N. Epidemiología de la hidatidosis en el Perú. En: Ministerio de Salud. Anales del Seminario Nacional de hidatidosis y enfermedades de transmisión alimentaria. Lima: MINSA; 1989. p. 122-137.

7. Castro S, Santamaría M, Grau S, et al. Rotura intraperitoneal traumática de quiste hidatídico hepático. Cir Esp. 2008; 84(1):45-54.

8. Fernández-Lahera $\mathrm{J}$, Mediano $\mathrm{O}$, Sarró $\mathrm{M}$, et al. Tránsito hepatotorácico de un quiste hidatídico hepático evolucionado. Rev Patol Respir. 2006; 9(3):141-142.

9. Castillo-De-la-Cadena L, Infante H, Torres W, et al. Ruptura aguda de quiste hidatídico hepático hacia tórax. Rev Med Hered. 2019; 30(2):110-114.

10. Kabiri E, El Maslout A, Benosman A. Thoracic rupture of hepatic hydatidosis (123 Cases). Ann Thorac Surg. 2001; 72(6):1883-1886.

11. Msaad S, Yangui I, Ketata W, et al. Kystes hydatiques du foie rompus dans le thorax (à propos de cinq cas). Rev Pneumol Clin. 2015; 71:255-263.

12. Armiñanzas C, Gutiérrez M, Fariñas M. Hidatidosis: aspectos epidemiológicos, clínicos, diagnósticos y terapéuticos. Rev Esp Quimioter. 2015; 28(3):116124.

13. Oumar T, Ibrahima K, Sitor S, et al. Kyste hydatique de la rate: à propos d'un cas. Pan African Med J. 2013; 14(92):1-4.

14. Ramos G, Duque J, Yuste J, et al. La ruptura intrapleural del quiste hidatídico de pulmón. Arch Bronconeumol. 1984; 20(2):47-54.

15. Morales J, Tapia C, Muñoz C. Reacción anafiláctica secundaria a quiste hidatídico hepático roto. Rev Chil Cir. 2011; 63(3):301-304.

16. Rodulfo J, Carrión M, Freitas M, et al. Hidatidosis pulmonar. Neumol Pediatr. 2013; 8(1):5-9.

17. Bastidas A, Velásquez J, Pérez C. Derrame pleural eosinofílico por hidatidosis hepática: presentación de caso clínico y revisión de la literatura. Rev Fac Med. 2008; 16(1):45-55.

18. Arif SH, Shams-Ul-Bari, Wani NA, et al. Albendazole as an adjuvant to the standard surgical management of hydatid cyst liver. Int J Surg. 2008; 6(6):448-451. doi:10.1016/j.ijsu.2008.08.003

19. Del-Carpio M, Mercapide C, Salvitti J, et al. Normas de diagnóstico y tratamiento de la hidatidosis humana. Provincia de Río negro: Ministerio de Salud; 2016. (Citado el 29 de junio de 2020). Disponible en: http:// www.uresaandina.com.ar/wp-content/uploads/ 2016/08/Normas_Diagnostico_Tratamiento Hidatidosis_2010.pdf

Recibido: $15 / 08 / 2020$

Aceptado: 28/12/2020 